\title{
Abordagem legislativa do trabalho doméstico assalariado: desafios para a igualdade material de gênero
}

\author{
Current legislative approach of paid domestic work: \\ challenges to substantive gender equality
}

\section{Daniela Fucci da Costa \\ danifucci@uol.com.br}

Graduanda em Direito pela PUC-Rio.

\begin{abstract}
Resumo
O trabalho doméstico assalariado é uma das principais ocupações das mulheres brasileiras. Entretanto, sua equiparação aos demais trabalhos urbanos e rurais veio apenas em 2013, após aprovação da PEC das Domésticas. O artigo analisa a atual abordagem legislativa acerca dessa categoria profissional e avalia se a legislação atual é capaz de garantir a essas trabalhadoras uma condição de igualdade de fato.

Palavras-chave: trabalho doméstico; abordagem legislativa; igualdade formal e material.
\end{abstract}

\begin{abstract}
Salaried domestic work is one of the main occupations of Brazilian women. However, its equalization to other urban and rural works came only in 2013, after the sanction of the "Domestic Worker's Amendment". This article analyzes the current legislative approach on the matter and evaluates whether the existing legislation is capable of assuring these workers a condition of substantive equality.
\end{abstract}

Keywords: domestic work; legislative approach; formal and substantive equality 


\section{Introdução}

O trabalho doméstico tem um papel enorme na vida das mulheres brasileiras. Quase a totalidade delas faz algum tipo de atividade doméstica, e muitas o fazem profissionalmente, ou seja, recebem uma remuneração para desempenhá-lo para terceiros. Embora seja uma das principais ocupações das mulheres no mercado de trabalho no Brasil, o trabalho doméstico remunerado só foi equiparado aos demais trabalhos urbanos e rurais em 2013, após aprovação da PEC das Domésticas, a PEC 66/2012, que veio a se tornar a EC nº 72/2013. Desde então, as empregadas domésticas têm direito a salário mínimo, férias remuneradas, aviso prévio e demais garantias.

Apesar de ser de tamanha importância para a inserção das mulheres no mercado de trabalho, a essa categoria não é concedida regulamentação específica. Em outras palavras, o trabalho doméstico assalariado, no Brasil, não é visto de forma adequada, de modo que a igualdade de fato dessas trabalhadoras nunca poderá ser atingida. Trata-se, mais especificamente, da negligência quanto ao recorte de gênero. Em nosso país, mais de $90 \%$ dos trabalhadores domésticos são mulheres ${ }^{1}$, portanto parece inconcebível que esse fato não seja levado em consideração na hora de elaborar legislações. Dessa forma, o que se pretende afirmar é que esse trabalho específico não pode ser tratado como qualquer outro, mas como uma questão intimamente ligada à promoção da igualdade de gênero, princípio este garantido pela Constituição Federal em seu artigo $5^{\circ}$, inciso I.

Nesse contexto, o presente artigo tem como foco o exame das abordagens que se fazem hoje acerca do trabalho doméstico remunerado, tendo em vista que o maior esforço legislativo já feito para essa categoria - a PEC das Domésticas - sequer mencionou o fato de esta ser uma atividade exercida em expressiva maioria por mulheres. Conforme exposto, trata-se de uma função marcada fundamentalmente pela divisão sexual do trabalho, estando, portanto, relacionada à igualdade de gênero, como defende Biroli (2018) e será analisado a seguir. A divisão sexual do trabalho segue um princípio que se baseia nas relações sociais de gênero.

A importância de se analisar o problema da forma apropriada está em fazer o que MacKinnon denominou de "política borboleta". Ela a define a partir do "efeito borboleta", o fenômeno pelo qual ações extremamente pequenas e simples, se tiverem o alvo certo, podem

\footnotetext{
${ }^{1}$ SARAIVA, Adriana; BELLO, Luiz; RENAUX, Pedro. No Dia da Mulher, estatísticas sobre trabalho mostram desigualdade. Disponível em:

<https://agenciadenoticias.ibge.gov.br/agencia-noticias/2012-agencia-de-noticias/noticias/20287-nodia-da-mulher-estatisticas-sobre-trabalho-mostram-desigualdade> Acesso em: 26 jun. 2019

DIGNIDADE RE-VISTA | ISSN2525-698X| 2020 | V. V | N. 9 ESP | Direitos Humanos, direitos para todos: pensando a igualdade material dos direitos. Pastoral Universitária Anchieta PUC-RIO.
} 
ter repercussões altamente complexas e amplas em determinados contextos ${ }^{2}$. Tal política consiste, portanto, em uma intervenção humana pequena, porém correta, que, feita em um sistema político instável, pode ter grandes e complexas reverberações ${ }^{3}$. Para que essa intervenção atinja os resultados esperados, entretanto, é imprescindível que se ataque o hipocentro do problema, e não apenas questões periféricas, identificando adequadamente a substância do sistema ao qual se dirige a intervenção (MACKINNON, 2019, p. 4).

Levando todo o exposto em consideração, este artigo pretende elucidar a relação entre trabalho doméstico remunerado e a promoção efetiva da igualdade de gênero. A partir disso, procura-se investigar como a abordagem legislativa brasileira atual dessa atividade, que exclui a questão de gênero, representa um obstáculo para que a igualdade seja de fato atingida.

\section{Divisão sexual do trabalho}

A divisão sexual do trabalho é a responsável por determinar o que é "trabalho de mulher" e o que não é, ou seja, discrimina funções de acordo com o gênero (BIROLI, 2018, p. 21). Desde seus primórdios, na transição do feudalismo para o capitalismo, ela definiu o trabalho reprodutivo doméstico como sendo incumbência feminina, o que depois acabou ficando invisibilizado e, hoje, se mascara como algo "natural" das mulheres. A divisão sexual do trabalho redefiniu o papel da mulher na sociedade e restringiu sua liberdade e autonomia. Embora tenha se desenhado muitos séculos atrás, quando as tarefas produtivas e reprodutivas, bem como as relações homem-mulher foram alteradas (FEDERICI, 2017, p. 30), os reflexos dessa divisão ainda se fazem presentes.

A grande ficção criada na época pré-capitalista e que nos assombra até os dias atuais é de que o trabalho doméstico reprodutivo, como dito, é uma função natural feminina. Como coloca Federici (2017, p.31), “a 'feminilidade' foi construída como uma função-trabalho que oculta a produção da força de trabalho sob o disfarce de um destino biológico". Sob essa perspectiva, essa função é desprovida de importância econômica, pois é algo inerente a todas nós, ou seja, não é um trabalho propriamente dito. Dessa forma, a reprodução da força de trabalho foi designada como "trabalho de mulheres" (FEDERICI, 2017, p. 145).

É importante salientar que "a divisão sexual do trabalho não se organizou historicamente segundo um padrão único" (BIROLI, 2018, p. 37). A essa questão são indispensáveis as

\footnotetext{
${ }^{2}$ Em tradução livre minha do trecho: "(...) how some extremely small simple actions, properly targeted, can come to have highly complex and large effects in certain contexts."

${ }^{3}$ Também em tradução própria do trecho: "Butterfly politics means the right small human intervention in an unstable political system can sooner or later have large complex reverberations."
}

DIGNIDADE RE-VISTA | ISSN2525-698X| 2020 | V. V | N. 9 ESP | Direitos Humanos, direitos para todos: pensando a igualdade material dos direitos. Pastoral Universitária Anchieta PUC-RIO. 
questões referentes a raça e classe, o que assimila posições diferentes entre as mulheres e os homens. Em última análise, porém, a divisão sexual do trabalho afeta a todas as mulheres como grupo (BIROLI, 2018, p. 35).

O fato de o trabalho doméstico ser considerado feminino - e esse pressuposto garantir a ele um status inferior - afeta diretamente na busca por emancipação das mulheres. Emancipação é aqui entendida como a busca por autonomia, sobretudo a autossuficiência econômica, que é o fator impeditivo mais comum que faz as mulheres se submeterem a situações degradantes. Nesse sentido, a divisão sexual do trabalho cria uma linha divisória entre as ocupações existentes, de modo que aquelas que são vinculadas ao suposto papel social feminino são sistematicamente menos remuneradas. Conforme sugere Biroli (2018, p. 48), "a remuneração pelo trabalho [se define] numa escala em que o que é historicamente associado ao feminino tem menor valor".

É essencial, portanto, que o trabalho doméstico assalariado seja encarado como uma questão marcada substancialmente pelo recorte de gênero, pois esse fator é crucial para que se entenda o porquê do tratamento desigual dessa categoria em relação aos demais trabalhos urbanos e rurais. Reconhecendo ser essa a raiz do problema, pode-se almejar ter as repercussões complexas anunciadas por MacKinnon.

\section{Implicações no Brasil}

Naturalmente, a divisão sexual do trabalho também está presente no Brasil. Um ponto importante afetado diretamente pela divisão sexual do trabalho é a participação feminina na política. Esta é uma relevante dimensão de análise quando pretendemos investigar a abordagem legislativa acerca do trabalho doméstico remunerado.

Atualmente, após as eleições de 2018, 77 mulheres foram eleitas para a Câmara dos Deputados, e outras 13 conseguiram chegar ao Senado Federal. Esses números formam um total de $15 \%$ e $16 \%$, respectivamente. Considerando que a população brasileira é composta em $51,4 \%$ por mulheres, pode-se afirmar que somos extremamente sub-representadas na política. Deve-se ressaltar que, ao se falar em emprego doméstico, as mulheres mais afetadas são mulheres negras de classes mais baixas. No que diz respeito a elas, sua representação é ainda mais ínfima, visto que, dentro dessas 90 mulheres que hoje ocupam o Congresso, apenas 13 delas se declaram pretas ou pardas.

A divisão sexual do trabalho não é, portanto, uma pauta prioritária no Legislativo brasileiro. Isso se dá devido a dois fatores (BIROLI, 2018, p. 45). O primeiro diz respeito ao 
fato de que os homens são maioria na política. Por estarem em uma posição confortável socialmente e serem beneficiados - em uma análise superficial, ao menos - pela divisão sexual do trabalho, não compartilham de muitas demandas femininas. Além disso, são também, em grande parte, brancos e de elite, o que os coloca na posição de patrões no caso das relações de trabalho com empregadas domésticas. Assim, não apenas não há representantes das demandas dessas mulheres, como há um interesse maior de que as dinâmicas de trabalho, em geral, e do trabalho doméstico, especificamente, não se alterem.

$\mathrm{O}$ segundo fator se refere às diferenças entre mulheres. Como dito anteriormente, a divisão sexual do trabalho também é uma questão afetada pelas variáveis de raça e classe. Nesse sentido, as mulheres eleitas para cargos políticos são aquelas pertencentes às elites, ou seja, as que têm maior renda e acesso a uma boa educação. O perfil encontrado entre as empregadas domésticas é o oposto, pois se trata de mulheres de classes mais baixas e pouco escolarizadas ${ }^{4}$. Isso faz com que os problemas suscitados pela divisão sexual do trabalho passem despercebidos enquanto um problema de gênero, uma vez que não se apresenta como tal na experiência das mulheres pertencentes às classes dominantes (CRENSHAW, 2002, p. 176 apud BIROLI, 2018, p. 46). Pelo contrário, o fato de as mulheres brancas e de elite não terem de lidar com o trabalho doméstico é um motivo pelo qual conseguem focar em outras áreas, como sua educação e inserção no mercado de trabalho formal e qualificado.

É correto afirmar, portanto, que a falta de preocupação legislativa com a questão de gênero é um elemento significativo que contribui para que o mercado de trabalho no Brasil reflita a configuração estabelecida pela divisão sexual do trabalho.

\section{Gênero e raça}

As relações sociais de gênero foram importadas junto com o processo de colonização. No que tange ao trabalho doméstico especificamente, o contexto brasileiro é ainda mais diferenciado por conta do enorme histórico de quase quatro séculos de escravidão. Nesse sentido, Preta Rara faz uma analogia entre o "quartinho de empregada" e a senzala, afirmando ser o primeiro uma versão moderna da segunda. Para a autora, o trabalho doméstico remunerado é "um grande resquício de uma abolição não conclusa” (PRETA-RARA, 2019, p. 28).

\footnotetext{
${ }^{4}$ GOVERNO DO BRASIL. Trabalho doméstico é a ocupação de 5,9 milhões de brasileiras. Disponível em: <https://bit.ly/2RBz5uM>. Acesso em: 25 jun. 2019 
É preciso contextualizar o trabalho doméstico assalariado no Brasil, cuja sociedade é marcada pelo racismo estrutural, o qual põe a população negra em posições inferiores em todos os espaços. Embora a abolição da escravidão tenha ocorrido no século XIX, os reflexos da escravidão ainda são sentidos, uma vez que pouco foi feito, politicamente, para garantir a equiparação - em todos os sentidos, social, político, econômico, de educação, entre outros - de brancos e negros. Em 2019, não se tem mais o senhor de engenho, a chibata, a senzala e a casagrande. Entretanto, há patroas que separam as louças que podem ser utilizadas pela empregada ou que a alimentam com as sobras das refeições do dia (PRETA-RARA, 2019, p. 10).

É comum a visão de que o trabalho traz libertação para as mulheres. Foi essa a posição defendida por feministas nos séculos XIX e XX. Essa visão, entretanto, faz uma análise muito superficial das mulheres enquanto grupo, visto que sua grande maioria, representada pelas classes mais baixas, sempre esteve no mercado de trabalho para garantir sua própria subsistência. Por esse motivo, muitas feministas negras consideram a perspectiva do "trabalho libertador" como uma "idealização fincada na experiência de mulheres brancas, com acesso a carreiras profissionais capazes de oferecer um grau relativamente elevado de autonomia e remuneração" (BIROLI, 2018, p. 38).

Tendo isso em vista, não cabe o argumento de que o trabalho doméstico remunerado é uma ferramenta para que as mulheres, sobretudo as mulheres negras, atinjam uma posição autossuficiente, ainda que ele seja a ocupação de quase 6 milhões de brasileiras 5 . Como leciona bell hooks, "quando falamos em autossuficiência como libertadora em vez de trabalho, precisamos dar o próximo passo e falar sobre qual tipo de trabalho é libertador" (HOOKS, 2019, p. 83). Evidentemente, o trabalho doméstico assalariado, nos termos em que se dá hoje no Brasil, não é capaz de oferecer às mulheres uma saída da dominação masculina. Embora tenha havido, em 2013, a equiparação dos direitos trabalhistas com os demais trabalhadores ${ }^{6}$, as empregadas domésticas ainda trabalham, em larga escala, na informalidade, ganhando, por isso, salários abaixo do mínimo estipulado em lei ${ }^{7}$.

Em 2015, 65\% das mulheres empregadas domésticas, no Brasil, eram mulheres negras. Em comparação com 1995, não somente cresceu o número de mulheres empregadas domésticas - quase um milhão a mais - como aumentou e $10 \%$ a proporção de mulheres negras

${ }^{5}$ GOVERNO DO BRASIL. Trabalho doméstico é a ocupação de 5,9 milhões de brasileiras. Disponível em: <https://bit.ly/2RBz5uM>. Acesso em: 25 jun. 2019

${ }^{6}$ Este tópico será abordado mais a fundo nas seções seguintes.

${ }^{7}$ ESTADÃO. Trabalho doméstico aumenta via informalidade, mas salários caem, diz IBGE. Disponível em: < https://bit.ly/2NieJIG> Acesso em: 27 jun. 2019 
domésticas $^{8}$. Essa estatística é um reflexo da forma pela qual as hierarquias sociais mantêm as mulheres negras na base da pirâmide social (PRETA-RARA, 2019, p. 11), com piores oportunidades e condições de trabalho. Mudar esses dados, garantindo acesso à educação e a outros empregos, por exemplo, é libertar as mulheres negras da posição de empregadas domésticas - o que remete diretamente às escravas domésticas do Brasil escravagista.

\section{Mercado de trabalho no Brasil}

No Brasil, o mercado de trabalho é composto pela população economicamente ativa (PEA), composta, por sua vez, segundo o Instituto Brasileiro de Geografia e Estatística (IBGE), por pessoas de 10 anos ou mais de idade, economicamente ativas ${ }^{9}$. Em 2015, a PEA consistia em 24,9 milhões de pessoas, dentre as quais 11,8 milhões eram mulheres.

Trata-se de uma conquista relativamente recente as mulheres poderem trabalhar fora de casa e em condições, ao menos formalmente, iguais. A divisão sexual do trabalho, entretanto, ainda se reflete na configuração do mercado de trabalho no Brasil.

\section{Trabalho feminino}

A partir do desenvolvimento da divisão sexual do trabalho exposto acima, deve-se chamar atenção a um aspecto em especial. Trata-se do fato de as mulheres ainda se concentrarem nas ocupações tidas, tradicionalmente, como femininas, além de participarem, em menor proporção, dos grupamentos ocupacionais que apresentam os maiores rendimentos médios.

Os estudos especiais sobre "Mulheres no Mercado de Trabalho", da recente Pesquisa Nacional por Amostra de Domicílios contínua (PNAD Contínua), realizada pelo IBGE em 2018 e divulgada no início de $2019^{10}$, demonstram que as mulheres são predominantes (55\%) nas ocupações elementares - que incluem trabalhadores domésticos, ajudantes de cozinha, pessoal de limpeza e parte dos vendedores ambulantes - e nas de trabalhadores de apoio administrativo

8 Disponível em: <http://ipea.gov.br/retrato/indicadores_trabalho_domestico_remunerado.html> Acesso em: 19 nov. 2019

${ }^{9}$ IBGE. Diretoria de Pesquisas, Coordenação de Trabalho e Rendimento, Pesquisa Mensal de Emprego mar.2002-fev.2016. Disponível em:

<ftp://ftp.ibge.gov.br/Trabalho_e_Rendimento/Pesquisa_Mensal_de_Emprego/Tabelas/2016/tab0090 22016.xls> Acesso em: 27 jun. 2019

${ }_{10}$ IBGE. PNAD Contínua - Divulgação Especial: Mulheres no Mercado de Trabalho. 2018. Disponível em:

<ttp:/ftp.ibge.gov.br/Trabalho_e_Rendimento/Pesquisa_Nacional_por_Amostra_de_Domicilios_contin ua/Estudos_especiais/Mulheres_no_Mercado_de_Trabalho_2018.pdf > Acesso em: 3 jul. 2019

DIGNIDADE RE-VISTA | ISSN2525-698X| 2020 | V. V | N. 9 ESP | Direitos Humanos, direitos para todos: pensando a igualdade material dos direitos. Pastoral Universitária Anchieta PUC-RIO. 
$(64,5 \%)$ - como secretárias, recepcionistas, caixas, entre outros ${ }^{11}$. Esses dados confirmam o que observa Federici (2019, p. 95), quando declara que, concentrando-se no setor de serviços que envolvem o trabalho reprodutivo, "as mulheres trocaram o trabalho doméstico não pago para sua família por trabalho doméstico pago no mercado".

A mesma pesquisa mostra que as duas ocupações mais bem remuneradas são as de diretores e gerentes e de membros das forças armadas, policiais e bombeiros militares. Há, respectivamente, $42 \%$ e $13 \%$ de participação feminina. Além disso, as mulheres constituem 63\% dos profissionais das ciências e intelectuais, dentre os quais se encontram engenheiros, físicos e químicos. Em uma primeira vista, este parece ser um dado que demonstra um avanço, tendo em vista a luta e a sub-representação feminina nas áreas exatas e técnicas. Contudo, quando se analisam os rendimentos, percebe-se que as mulheres recebem o equivalente a $64,8 \%$ do que ganham os mesmos profissionais do sexo masculino ( $\mathrm{R} \$ 3.819$ e $\mathrm{R} \$ 5.890$, respectivamente). O mesmo ocorre em relação às mulheres médicas e advogadas, que, embora representem mais da metade do total de profissionais, recebem pouco mais de $70 \%$ dos ganhos de seus colegas homens.

Por fim, deve-se destacar, naturalmente, a categoria dos trabalhadores domésticos assalariados. Essa ocupação é aquela, na qual há maior predominância de mulheres (95\%). Não por acaso, conta com o menor rendimento médio entre todas as profissões ( $\mathrm{R} \$ 855)$, estando, inclusive, abaixo do salário mínimo estipulado atualmente, que corresponde a $\mathrm{R} \$ 998^{12}$. Nesse sentido, essa estatística está em conformidade com o que afirma Biroli (2018, p. 48). De acordo com a autora, "a remuneração pelo trabalho define-se uma escala em que o que é historicamente associado ao feminino tem menor valor".

\section{Legislação vigente acerca do trabalho doméstico}

Em 2018, a população ocupada do Brasil correspondia a quase 92 milhões de pessoas ${ }^{13}$. Dentre elas, 6,2 milhões eram ocupadas como trabalhadoras domésticas ${ }^{14}$, o que corresponde a

11 IBGE. Classificação de Ocupações para Pesquisas Domiciliares. Disponível em: <ftp://ftp.ibge.gov.br/Censos/Censo_Demografico_2010/metodologia/anexos/anexo_7_ocupacao_cod .pdf> Acesso em: 5 jul. 2019

${ }_{12}$ FERNANDES, Talita; URIBE, Gustavo. Bolsonaro eleva salário mínimo para R\$ 998, primeiro aumento real em três anos. Disponível em:

<https://www1.folha.uol.com.br/mercado/2019/01/bolsonaro-vai-assinar-decreto-que-reajusta-salariominimo-para-r-998.shtml> Acesso em: 5 jul. 2019

${ }^{13}$ Disponível em:

<ftp://ftp.ibge.gov.br/Trabalho_e_Rendimento/Pesquisa_Mensal_de_Emprego/Tabelas/2016/tab0250 22016.xls> Acesso em 5 jul. 2019

${ }^{14}$ Disponível em:

DIGNIDADE RE-VISTA | ISSN2525-698X| 2020 | V. V | N. 9 ESP | Direitos Humanos, direitos para todos: pensando a igualdade material dos direitos. Pastoral Universitária Anchieta PUC-RIO. 
6,8\% do total dessa população. De acordo com a Classificação Brasileira de Ocupações (CBO), por "trabalhadores dos serviços domésticos em geral" entendem-se aqueles que preparam refeições, colaboram na administração da casa, fazem faxina, cuidam de plantas e animais domésticos, entre outros ${ }^{15}$.

Às trabalhadoras domésticas assalariadas não eram concedidos os mesmos direitos e benefícios a que tinham acesso os demais trabalhadores. Esse panorama se alterou apenas em 2013, com a aprovação da proposta de emenda constitucional que ficou conhecida como a PEC das Domésticas (Proposta de Emenda à Constituição no 66 de 2012). A PEC teve como justificativa a equiparação de direitos trabalhistas entre os trabalhadores domésticos e os demais trabalhadores urbanos e rurais.

A PEC deu origem à Emenda Constitucional n ${ }^{\circ}$ 72, a qual alterou a redação do parágrafo único do art. $7^{\circ}$ para estabelecer a igualdade de direitos trabalhistas para os trabalhadores domésticos. É importante chamar atenção ao fato de que essa emenda não garantiu a totalidade de direitos elencados na Consolidação das Leis do Trabalho (CLT). A CLT prevê, em seu art. $7^{\circ}$, "a", que os preceitos constantes nela não se aplicam aos empregados domésticos ${ }^{16}$. Esse dispositivo continua tendo eficácia mesmo após a aprovação da PEC das Domésticas, o que significa que a elas são garantidos apenas os direitos expressamente mencionados pelo parágrafo único do art. $7^{\circ}$ da Constituição.

Após a entrada em vigor da emenda constitucional, a então presidenta Dilma Rousseff sancionou a Lei Complementar n ${ }^{\circ} 150$, responsável por regulamentá-la. A lei dispõe sobre o contrato de trabalho doméstico e define o empregado como sendo "aquele que presta serviços de forma contínua, subordinada, onerosa e pessoal e de finalidade não lucrativa à pessoa ou à família, no âmbito residencial destas, por mais de 2 (dois) dias por semana”. Nela fixaram-se a jornada de trabalho, as férias remuneradas, a indenização em decorrência de rescisão do contrato de trabalho, além das causas que justificam a rescisão do contrato por culpa do empregador, entre outros. Esse dispositivo legal foi, assim, determinante para estabelecer limites à relação entre empregador e empregada, sobretudo ao primeiro, dado que, anteriormente, as condições contratuais eram todas definidas com base no acordo entre as partes. Com essa regulamentação, a extensão dos direitos das domésticas se concretizou.

$<\mathrm{ftp} / / / \mathrm{ftp}$.ibge.gov.br/Trabalho_e_Rendimento/Pesquisa_Nacional_por_Amostra_de_Domicilios_contin ua/Principais_destaques_PNAD_continua_2012_2018/PNAD_continuā_retrospectiva_2012_2018.pdf $>$ Acesso em: 3 jul. 2019

15 Disponível em: <http://www.mtecbo.gov.br/cbosite/pages/pesquisas/BuscaPorTituloResultado.jsf> Acesso em: 5 jul. 2019

16 BRASIL. CLT. Aprova a Consolidação das Leis do Trabalho. Disponível em: <http://www.planalto.gov.br/ccivil_03/decreto-lei/del5452.htm> 
O que se pretendia tanto com a emenda à Constituição, quanto com a LC nº 150 , era promover melhores condições de trabalho para as domésticas. Entretanto, elas só têm direito às garantias legais se estiverem em uma relação formal de trabalho. Nesse sentido, deve-se elucidar que mais direitos às trabalhadoras também implica mais encargos aos empregadores, pois devem arcar não somente com os salários - que, quando se trata de trabalho informal, são mais baixos -, como também com as garantias e benefícios a que têm direito as empregadas.

No âmbito jurisprudencial, havia a discussão acerca da caracterização do vínculo de emprego doméstico quando o trabalho era prestado três vezes na semana ${ }^{17}$. Esse impasse foi resolvido pela $\operatorname{LC} \mathrm{n}^{\circ} 150$, que expressamente define sua aplicação à empregada doméstica que preste serviços por mais de dois dias na semana. A nova lei revogou a Lei $n^{\circ} 5.859$, de 1972, chamada Lei do Empregado Doméstico, a qual não especificava a quantidade de dias a partir da qual se configura a relação de trabalho.

A redação da LC150 é mais favorável às empregadas domésticas, pois encerra a discussão e impede que se façam interpretações no sentido de restringir seus direitos. No caso de não reconhecimento do vínculo, trata-se não de empregada doméstica, mas de diarista, que não conta com as garantias trabalhistas. Assim, é uma forma de os patrões se eximirem do pagamento das garantias devidas, pois não caracterizam a relação como sendo de trabalho doméstico propriamente. Entretanto, é necessário ressaltar que, por causa da segurança jurídica, a lei não se aplica às relações iniciadas e findadas antes de sua promulgação. Do mesmo modo, se a relação for anterior, mas ainda existir, somente poderá ser apreciado o tempo da relação que coincide com a vigência da lei. Com isso, muitas trabalhadoras ainda não têm seus direitos reconhecidos por causa da indeterminação do termo "contínuo", que caracteriza a relação de trabalho doméstica, e da divergência jurisprudencial a respeito.

O total de pessoas ocupadas como empregadas domésticas sem carteira de trabalho - ou seja, sem as garantias previstas - aumentou, quando comparamos os números referentes a 2012, ano anterior à emenda, e 2018. Atualmente, 4,4 milhões de empregadas trabalham sem carteira, ganhando, em média, 740 reais ao mês. Em comparação, 1,8 milhões trabalham com carteira assinada, recebendo, assim, 1.245 reais, em média, por mês. Dessa forma, pode-se argumentar que as mudanças legislativas não atingiram integralmente seus objetivos, pois não há um número maior de pessoas que efetivamente desfrutando dos direitos estendidos a elas.

Não há como se estabelecer uma relação de causa e efeito exclusiva entre a implementação da legislação e o aumento do número de trabalhadoras informais, uma vez que

17 Cf. TST - RR: 19331320105150067, Data de Julgamento: 12/08/2015; TST - RR:

588006320085010074, Relator: Lelio Bentes Corrêa, Data de Julgamento: 20/09/2017, $1^{\text {a }}$ Turma. 
se teria de avaliar também os impactos de mudanças políticas e econômicas no país durante o período mencionado. Entretanto, há de se considerar que uma das principais razões por trás da aprovação dos novos instrumentos normativos era justamente a de trazer as empregadas domésticas para o trabalho formal e garantir-lhes, com isso, a totalidade de seus direitos ${ }^{18}$.

A PEC das Domésticas, como apresentado, teve como justificativa apenas a equiparação de direitos aos demais trabalhadores. Assim, não houve menção ao fato de que, segundo a PNAD Contínua publicada pelo IBGE em 2019, 95\% dos empregos domésticos são ocupados por mulheres ${ }^{19}$. Tratando-se de uma maioria tão expressiva, parece negligente ela não ser levada em consideração quando da elaboração de propostas legislativas referentes a essa área. Fosse o trabalho doméstico reconhecido como uma questão que diz respeito diretamente aos direitos das mulheres, ele ganharia uma outra roupagem. Com esse reconhecimento, a matéria deixaria de ser apenas uma matéria trabalhista e começaria a ser enfrentada como uma questão de igualdade de gênero propriamente. Desse modo, a regulamentação do trabalho doméstico e outras iniciativas a esse respeito seriam matéria de políticas públicas voltadas à população feminina. Uma forma de levar em conta a questão de gênero presente no trabalho doméstico remunerado, portanto, seria reconhecer que se trata de um trabalho desempenhado quase totalmente por mulheres.

Se analisadas as condições às quais as trabalhadoras domésticas se submetem, pode-se perceber que elas estão sujeitas a inúmeras violências de gênero. Um exemplo já citado é a desvalorização da atividade, refletida nos rendimentos médios - tão discrepantes em relação às demais profissões -, que pode ser interpretada como resultado de discriminação com base em gênero, considerando ser desempenhada majoritariamente por mulheres.

A Convenção ${ }^{\circ} 189$ da Organização Internacional do Trabalho (OIT) - ratificada pelo Brasil no início de 2018 - dispõe acerca do trabalho decente para as trabalhadoras e os trabalhadores domésticos. $\mathrm{O}$ instrumento traz alguns avanços em relação à legislação nacional, pois reconhece a questão de gênero. Nas disposições iniciais, reconhece ser o trabalho doméstico uma atividade subvalorizada e invisível, executada predominantemente por mulheres e meninas ${ }^{20}$. Além disso, a Convenção também deixa expressa a obrigação dos Estados membros de assegurar que a remuneração das trabalhadoras domésticas não seja

\footnotetext{
${ }^{18}$ Tal afirmação se depreende a partir da justificação apresentada no texto inicial da PEC no 66 de 2012. Disponível em: <https://legis.senado.leg.br/sdleggetter/documento?dm=4083999\&ts=1567531136766\&disposition=inline $>$ Acesso em: 13 nov .2019 ${ }_{19} \mathrm{Em} 2012$, ano em que a PEC foi apresentada, a proporção de mulheres era igualmente significativa, de $92 \%$.

${ }^{20}$ Disponível em: <https://www2.camara.leg.br/legin/fed/decleg/2017/decretolegislativo-172-4dezembro-2017-785852-convencao-154384-pl.html> Acesso em: 20 nov. 2019
} 
estabelecida com base em discriminação por sexo. Seria interessante uma disposição similar expressa na LC 150, embora uma interpretação sistemática do ordenamento jurídico brasileiro permita concluir que já há a vedação de remuneração diferenciada por sexo.

Foram feitos, portanto, avanços significativos no sentido de garantir às trabalhadoras domésticas assalariadas uma melhor condição de trabalho e ampliação de direitos. No entanto, os esforços legislativos ainda são insuficientes - principalmente no que diz respeito ao recorte de gênero -, muitas vezes não atingem os resultados esperados e têm sua aplicação ainda dificultada. Como aponta MacKinnon, estratégias legais que preferem lidar com dinâmicas periféricas podem ter, sim, alguns efeitos positivos, porém não podem ter a expectativa de mudar grandes estruturas. (MACKINNON, 2019, p. 4).

\section{Teorias de igualdade}

Quando falamos e lemos "igualdade”, o conceito que vêm à nossa cabeça é o de igualdade formal. Embora pareça um entendimento intuitivo, é possível distinguir, dentro da noção de igualdade, duas abordagens diversas: a da igualdade formal e a da igualdade material. A igualdade de direitos que se deu com a PEC das Domésticas de 2013 se encaixa no que MacKinnon define como igualdade formal.

O que se busca averiguar é se a nova legislação foi capaz de promover a igualdade efetivamente. Para isso, faz-se necessário elucidar ambos os conceitos, de igualdade formal e material, conforme apresentados por MacKinnon (MACKINNON, 1989 e 2019).

\section{Igualdade formal}

Igualdade formal - a que se pode referir também como "vedação de diferenciação" (Differenzierungsverbot $)^{21}$ - corresponde à fórmula aristotélica de "likes alike, unlikes unalike", ou seja, a igualdade consistiria no tratamento igual de pessoas iguais (MACKINNON, 2019, p. 306). O problema que envolve essa máxima de Aristóteles é que ela negligencia o fato de que as pessoas podem ser diferentes entre si, e ainda assim iguais em direitos ${ }^{22}$, devendo ser tratadas dessa forma (MACKINNON, 2019, p. 312).

Essa abordagem pretende adotar uma posição de neutralidade frente ao gênero, proibindo que se leve essa questão em consideração, pois isso significaria uma forma de discriminação.

\footnotetext{
${ }^{21}$ Esta denominação (em tradução livre) foi apresentada por Ute Sacksofsky em: SACKSOFSKY, 2013.

22 O termo "igual" aqui é empregado no sentido de "equal", em língua inglesa. 
No entanto não se deve perder de vista que a neutralidade de gênero segue o padrão masculino (MACKINNON, 1989, p. 221), ou seja, os padrões que devemos seguir socialmente são aqueles correspondentes a um homem branco, de elite, sem deficiências físicas, heterossexual e de uma idade específica (MACKINNON, 2019, p.117). Em um contexto desigual, a neutralidade tende a perpetuar o status quo, o que faz com que as políticas públicas criadas com a intenção de promover igualdade façam prevalecer as desigualdades já existentes. A neutralidade de gênero tem como fundamento a "cegueira de gênero" (gender blindness), de acordo com a qual as desigualdades devem ser ignoradas para produzir resultados que reflitam equidade (MACKINNON, 2019, p. 312). Enquanto isso, situações nas quais há de fato equidade são estigmatizadas como "proteção especial ou ações afirmativas", em vez de simplesmente serem reconhecidas como igualdade (MACKINNON, 1989, p. 233).

Sob a ótica da igualdade formal, as políticas de igualdade focam na diferença. Como efeito, elas neutralizam e omitem disparidades de poder, pois ignoram as hierarquias sociais existentes. As mulheres beneficiadas por essa perspectiva política são as pertencentes às elites, que se aproximam do padrão masculino, ao menos formalmente. Quando essas pessoas sofrem discriminação, a desigualdade de gênero se torna mais evidente (MACKINNON, 1989, p. 225). Naturalmente, as discriminações não se limitam a essa classe de mulheres.

\section{Igualdade material}

Para remediar as lacunas deixadas pela teoria da igualdade formal, MacKinnon introduz a abordagem da igualdade material - ou "vedação de dominação" (Dominierungsverbot). Na primeira, o gênero é considerado apenas como uma questão de semelhança (sameness) e diferença, o que tem como efeito mascarar a real dinâmica de gênero enquanto hierarquia social (MACKINNON, 1989, p. 218). O fato de que as mulheres vivem como integrantes de uma sociedade que discrimina com base em sexo não pode ser levado em consideração, pois, se assim o for, configuraria uma discriminação sexual. Na segunda, por outro lado, o gênero se encaixa em um contexto de hierarquia.

A igualdade material não se preocupa com as diferenças entre homens e mulheres, visto que ambos são iguais e diferentes na mesma medida. Ela reconhece que essas diferenças os fazem ocupar posições diferentes na hierarquia social. Assim, não enfrenta os problemas como questões de diferença e semelhança, mas como questões de dominação e subordinação.

Nessa perspectiva, as ações afirmativas são consideradas como medidas em busca de equidade, dado que a abordagem visa a combater padrões sistêmicos de privilégios 
(MACKINNON, 2019, p. 306). Não são, portanto, de forma alguma consideradas como discriminação, pois promovem, efetivamente, a igualdade. Em uma abordagem de igualdade formal, o tratamento diferenciado que visa ao combate de desigualdades é visto como ilegal quando se tem a garantia de que homens e mulheres são iguais perante a lei. A igualdade material, dessa forma, não pretende omitir as diferenças, mas acabar com as hierarquias sociais decorrentes delas.

\section{Emprego doméstico "igual"}

A partir da elucidação das teorias da igualdade formal e material, pode-se argumentar que não houve promoção de igualdade de direitos entre trabalhadoras domésticas e demais trabalhadores, assim como o emprego doméstico não é igual aos demais. O Brasil adota a abordagem da igualdade formal, por isso, como coloca MacKinnon (1989, p. 223), "porque não há um homem para determinar um padrão de tratamento do qual o tratamento às mulheres pode desviar, também não há discriminação de gênero, apenas uma diferença entre os sexos" ${ }^{23}$. Este é o caso do trabalho doméstico assalariado, no qual há uma maioria expressiva de $95 \%$ de mulheres. Em outras palavras, conceder os mesmos direitos e as mesmas condições de trabalho - o que nem chega a ser o caso - não é suficiente para atingir a equidade se forem ignoradas as relações sociais hierárquicas que marcam a profissão.

A Constituição brasileira, em seu art. $7^{\circ}, \mathrm{XX}$, prevê a "proteção do mercado de trabalho da mulher, mediante incentivos específicos, nos termos da lei”. Essa disposição se caracteriza como um esforço que o Estado deve desempenhar para garantir a igualdade material de gênero no âmbito do trabalho. Nesse sentido, a insuficiência legislativa em relação à regulamentação do trabalho doméstico assalariado pode ser interpretada como uma omissão do Estado que atenta contra as previsões da Constituição, uma vez que o emprego doméstico concentra uma parcela significativa das mulheres inseridas no mercado de trabalho.

A abordagem da igualdade formal, associada à ficção criada em volta da 'feminilidade' pela divisão sexual do trabalho, dá origem a um entrave à igualdade de direitos das trabalhadoras domésticas assalariadas. Sob a ótica da igualdade formal, conceitos como dignidade acabam preenchendo o vazio deixado pela desconsideração das hierarquias sociais (MACKINNON, 2019, p. 314). Dessa forma, igualdade e dignidade se confundem de modo que a privação de dignidade é compreendida como sinônimo de desigualdade. De fato, a

\footnotetext{
${ }^{23} \mathrm{Em}$ tradução livre própria do trecho: "difference doctrine says that because there is no man to set a standard from which women's treatment is a deviation, there is no sex discrimination, only a sex difference."
}

DIGNIDADE RE-VISTA | ISSN2525-698X| 2020 | V. V | N. 9 ESP | Direitos Humanos, direitos para todos: pensando a igualdade material dos direitos. Pastoral Universitária Anchieta PUC-RIO. 
ausência de dignidade é uma parte importante da desigualdade, porém não envolve todo o problema (MACKINNON, 2019, p. 313). Como consequência, o trabalho doméstico assalariado, por não ser visto como algo indigno - já que é uma função naturalmente feminina, e a sociedade não considera as mulheres privadas de dignidade - também não é visto como algo discriminatório e desigual ${ }^{24}$. Esta acaba se tornando mais uma forma de dizer que não é desigual, apenas diferente. Se a desigualdade for compreendida através de sua substância hierárquica, esse problema desaparece (MACKINNON, 2019, p. 314).

O trabalho doméstico assalariado, portanto, não é marcado pela desigualdade porque é um trabalho privado de dignidade, mas porque envolve questões de gênero que implicam uma desigualdade econômica, por exemplo, tendo em vista que é a ocupação que tem os menores rendimentos. Em função disso, o recorte de gênero não pode ser negligenciado pelos esforços que pretendem garantir igualdade às (aos) trabalhadoras (es) domésticas (os).

\section{Considerações finais}

A partir do conteúdo exposto, é possível concluir que a atual abordagem legislativa acerca do trabalho doméstico assalariado de fato não somente não é capaz de garantir a essas trabalhadoras uma condição de igualdade material, como também é responsável por manter o status quo de desigualdade. Se quisermos de fato proporcionar igualdade a essas mulheres, é necessário utilizarmos a "política borboleta" de MacKinnon (2019), segundo a qual apenas identificando a verdadeira substância do problema é que se pode elaborar uma política que vá ter os efeitos desejados de mudar estruturas. É inegável que a questão de gênero é parte essencial da discussão do trabalho doméstico, tanto remunerado como não remunerado. Portanto, ela deve ser o foco dos esforços legislativos referentes à categoria.

Embora haja o argumento de que usar a questão de gênero implica uma política não neutra, e, por isso, incapaz de atingir igualdade, a abordagem da igualdade material o refuta. Em um contexto de desigualdade estrutural, medidas neutras perpetuam a desigualdade, por isso devemos optar por medidas que alterem essa configuração.

O custo social do trabalho doméstico assalariado é muito grande. Não apenas consolida o imaginário de que trabalho doméstico é trabalho de mulher, como também reforça o pensamento de que as mulheres brancas de elite podem comprar sua liberdade a partir da contratação de mulheres negras, que assumem, com isso, seus afazeres domésticos. É preciso

\footnotetext{
${ }^{24}$ No livro, MacKinnon utiliza o assédio sexual como exemplo dessa conduta. DIGNIDADE RE-VISTA | ISSN2525-698X| 2020 | V. V | N. 9 ESP | Direitos Humanos, direitos para todos: pensando a igualdade material dos direitos. Pastoral Universitária Anchieta PUC-RIO.
} 
que as mulheres brancas não tenham de se apoiar no trabalho das mulheres negras para conquistarem sua autonomia, da mesma forma que é preciso que o trabalho doméstico remunerado não seja uma das únicas opções de trabalho para mulheres negras.

Sob a perspectiva de que gênero e raça constituem um sistema de hierarquia social, é possível alterar a essência das normas estabelecidas. De acordo com a colocação de John Stuart Mill (2013, p. 29), “onde haja uma classe dominante, uma grande parte da moralidade nacional emana dos seus interesses de classe e dos seus sentimentos de superioridade de classe". 


\section{Referências bibliográficas}

BIROLI, Flávia. Gênero e desigualdades: os limites da democracia no Brasil. São Paulo: Boitempo, 2018

CRENSHAW, Kimberlé. Documento para o encontro de especialistas em aspectos da discriminação racial relativos ao gênero. In: Revista Estudos Feministas, ano 10, 2002, p. 17188

FEDERICI, Silvia. Calibã e a bruxa: mulheres, corpo e acumulação primitiva. Coletivo Sycorax. São Paulo: Elefante, 2017

O ponto zero da revolução: trabalho doméstico, reprodução e luta feminista. Coletivo Sycorax. São Paulo: Elefante, 2019

HOOKS, bell. O feminismo é para todo mundo: políticas arrebatadoras. Bhuvi Libânio. Rio de Janeiro: Rosa dos Tempos, 2019

MACKINNON, Catharine A. Butterfly Politics. Cambridge, Massachusetts: The Belknap Press of Harvard University Press, 2019

Press, 1989

Toward a Feminist Theory of the State. Cambridge, Massachusetts: Harvard University

MILL, John Stuart. Ensaio sobre a liberdade. 2013. Disponível em: $<$ https://direitasja.files.wordpress.com/2013/09/mill-john-stuart-ensaio-sobre-a-

liberdade.pdf $>$. Acesso em: 26 jun. 2019

PRETA-RARA. Eu, empregada doméstica: a senzala moderna é o quartinho da empregada. Belo Horizonte: Letramento, 2019

SACKSOFSKY, Ute. Antidiskriminierungsrecht, Diversität und Hochschulen. In: BENDER, Saskia-Fee, SCHMIDBAUR, Marianne; WOLDE, Anja. (Org.) Diversity ent-decken. Reichweiten und Grenzen von Diversity Policies an Hochschulen. 1. ed. Hemsbach: Beltz Juventa, 2013, p. 97-113 